\title{
Review
}

\section{Pulsatility of insulin and glucagon release: physiological significance and pharmacological implications}

\author{
P. J.Lefèbvre ${ }^{1}$, G. Paolisso ${ }^{1}$, A.J.Scheen ${ }^{1}$ and J.C. Henquin ${ }^{2}$ \\ ${ }^{1}$ Division of Diabetes, Institute of Medicine, University of Liège, Liège, Belgium and \\ ${ }^{2}$ I. Physiologisches Institut, Universität des Saarlandes, Homburg/Saar, Federal Republic of Germany
}

\begin{abstract}
Numerous endocrine systems are characterised by pulsatile hormone secretion with periodicities ranging from minutes to hours [1]. Such endocrine rhythms have been described among others for growth hormone, prolactin, gonadotropins, parathyroid hormone and corticosterone. The oscillatory pattern of plasma hormone levels may be physiologically important to reduce down regulation of receptors and, consequently, to enhance hormone action. Intermittent administration of hormones is now widely used in therapeutics since pulsatile administration of growth hormone releasing factor [2] or gonadotropin-releasing hormone [3] appears to be more efficient than continuous delivery.
\end{abstract}

Though circumstantial evidence for the existence of fluctuations in plasma glucose and insulin levels was published earlier, the current interest in the pulsatility of pancreatic hormones secretion dates from the now classical study of Goodner et al. [4]. Ten years after its publication, we will review the available data on the existence of oscillations in peripheral and, when available, portal levels of insulin and glucagon both in animals and in man. In vitro data on pulsatile insulin and glucagon release will be reviewed, with emphasis on the mechanisms involved and possible relationships with oscillations in B-cell-membrane potential. Comparative effects of pulsatile and continuous insulin and glucagon delivery will then be analysed. Finally, the potential importance of the mode of insulin delivery for the management of diabetes mellitus will be briefly considered.

\section{Oscillations in plasma concentrations of insulin and glucagon}

\section{In man}

The first description of blood glucose oscillations in man was made more than 60 years ago [5] and was confirmed by several subsequent studies [6-8]. Demon- stration of oscillations in the circulating levels of pancreatic hormones is only 10 years old. In fact, early studies, performed in three normal subjects submitted to $2 \mathrm{~min}$ sampling for $2 \mathrm{~h}$, failed to evidence regular oscillations of plasma glucose, insulin and glucagon; glucose and insulin, however, did display intermittent synchronous fluctuations of small amplitude [4]. In a study reported in 1979 by Lang et al. [9] plasma samples were collected at 1-min intervals from 10 normal subjects for periods lasting from 1-2 $\mathrm{h}$. In five of these subjects, basal plasma insulin levels cycled regularly with a mean period of $13 \mathrm{~min}$, and a mean amplitude of $1.6 \mathrm{mU} \cdot 1^{-1}$. A concurrent plasma glucose cycle was demonstrated with a mean amplitude of $0.05 \mathrm{mmol}$. $1^{-1}$; the average plasma glucose cycle was $2 \mathrm{~min}$ in advance of the plasma insulin cycle (Fig.1). In the subjects with less regular plasma insulin cycles, a similar plasma glucose rise was demonstrated 2 min before the insulin rise. These phase relations suggested the existence of a negative feedback loop between the liver and pancreatic $B$ cells, that might regulate both plasma insulin and glucose concentrations. The possibility that B cells could be stimulated by a cyclic, glucose-independent input was not ruled out, however [9]. The existence of plasma insulin cycles was confirmed by the same group [10] in a larger series of 28 subjects in whom the mean period averaged $10.7 \mathrm{~min}$ and the mean amplitude $1.1 \mathrm{mU} \cdot 1^{-1}$. Glucagon cycles were also demonstrated with a mean period of $13.7 \mathrm{~min}$ and a mean amplitude of $5.5 \mathrm{ng} \cdot 1^{-1}$. There was a significant correlation between the amplitude of simultaneous plasma insulin and glucagon cycles and cross-correlation showed that the changes in plasma glucagon levels lagged only 2 min behind the changes in plasma insulin levels. In another study, also performed in fasted volunteers [11], plasma levels of insulin were found to oscillate with a sustained periodicity of 11-13 min. The periodicity was similar $(10-13 \mathrm{~min})$ for plasma glucose levels, but ranged from 7 to $26 \mathrm{~min}$ for plasma glucagon levels. No consistent relationship could be found by cross-correlation analysis between the periodic fluc- 
Cycles defined by autocorrelation period
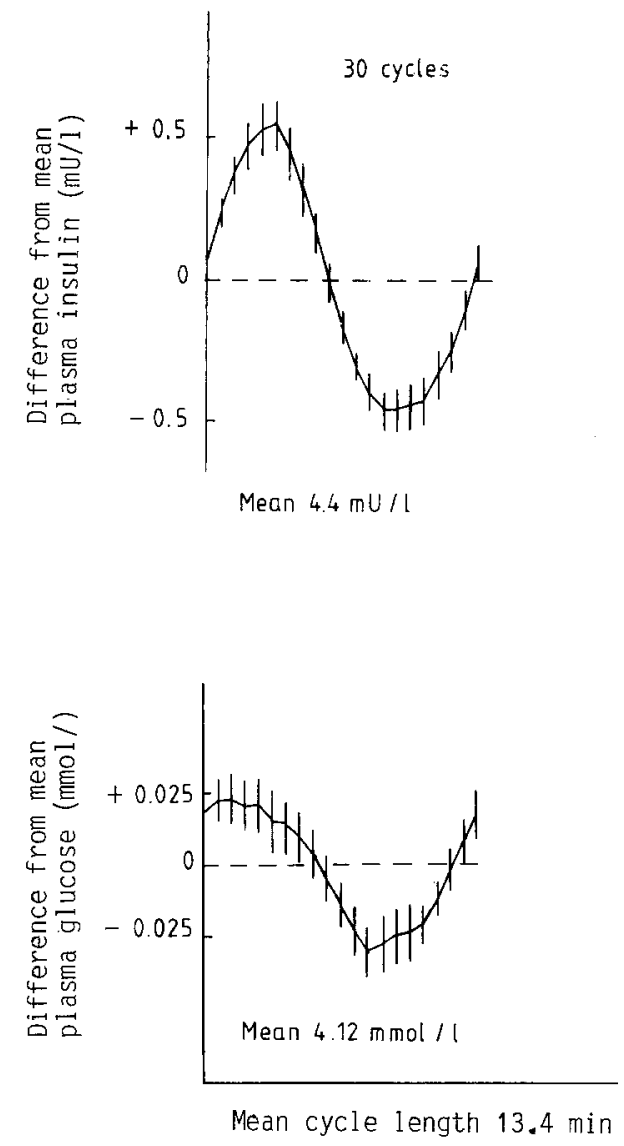

Fig. 1. Insulin and glucose cycles in normal man. Data obtained using the "standard array-averaging technique". The curves show the mean \pm SEM plasma insulin and glucose changes in five subjects. The plasma glucose oscillation precedes the insulin by $2 \mathrm{~min}$. The mean plasma insulin amplitude was $1.0 \mathrm{mU} / 1$ after averaging the standard array, but $1.6 \mathrm{mU} / 1$ when estimated by the differences between troughs and peaks of individual cycle. From Lang et al. [9]. Reproduced with permission of the copyright holder

tuations in insulin, glucose and glucagon. Taken together, these observations made it unlikely that fluctuations in glucose levels were driving pulsatile secretion by $A$ and $B$ cells. A further large series of normal subjects was studied in an attempt to identify the pacemaker mechanisms of these oscillations in hormone release [12]. It was shown that, in the basal state, pulsation frequency of insulin was stable through cholinergic, endorphin, $\alpha$-adrenergic or $\beta$-adrenergic blockade. Small pulses of glucose or insulin also failed to reset the cycles. Moreover, stimulations of insulin secretion with glucose, tolbutamide or sodium salicylate increased the amplitude of insulin oscillations without changing their period [12].

Plasma glucose and pancreatic hormone oscillations were also studied in a few pathological states. In obese subjects, the periodicity of the oscillations in plasma insulin, glucagon and glucose was similar to that observed in the normal weight subjects [11]. In contrast, in Type 2 (non-insulin-dependent) diabetic patients, the oscillations in basal plasma insulin were irregular [13] and the associated glucose swings were about six-fold larger than in normal subjects [12]. Variable results were obtained in six vagotomised patients [12]. Two of them showed regular plasma insulin oscillations in the normal range, while three others had longer periodicities and one subject had irregular changes. Interestingly, the fluctuations in plasma glucose levels were larger and exhibited a longer period in those vagotomised patients than in control subjects. In two patients who had undergone resection of the head of the pancreas (Whipple's operation), plasma insulin levels displayed long-term oscillations with a mean period of $37 \mathrm{~min}$ [12]. It should also be noted that besides these "rapid" fluctuations, large concomitant oscillations of insulin and $\mathrm{C}$-peptide levels, with an average period of $80 \mathrm{~min}$, have been described in normal man during continuous enteral infusion [14].

The results of all these studies in man have led to the proposal [13] that the $12-13 \mathrm{~min}$ cycle of insulin levels is due to cyclic hormonal release under the control of a pancreatic pacemaker that could be localised in the head of the organ, and that does not involve adrenergic, muscarinic or endorphin receptors. This pacemaker could be under vagal control and function within the context of a feed-back loop (period $30-40 \mathrm{~min}$ ) between glucose production by the liver and insulin release by the $B$ cells.

\section{In animals}

In a single dog, Anderson et al. [15] reported rapid (period of less than $1 \mathrm{~min}$ ) oscillations in basal concentrations of pancreatic venous insulin and hepatic venous glucose. These oscillations tended to show synchrony for about half of a 6-min period. In a more recent and complete study also performed in the dog [16], frequent sampling from the portal vein revealed basal, spontaneous oscillations of all four pancreatic peptides. Moreover, the pulsatility of C-peptide levels was remarkably parallel to that of insulin, whereas glucose fluctuations were inconsistent. Insulin and glucagon oscillations were the most prominent, were in phase and had a period of $10-14$ min. Pulses of pancreatic polypeptide were less frequent, though always associated with insulin pulses. Somatostatin pulses were less consistently associated with those of other peptides [16]. Interestingly, in one of nine dogs, pulsatility of all four hormones included components of both shorter and longer periods. In longer experiments (up to $12 \mathrm{~h}$ ) carried out in fasted dogs, less frequent blood sampling (every 7.5-15 min) evidenced slow fluctuations in portal and peripheral concentrations of insulin, glucagon and somatostatin, whereas glucose levels did not significantly fluctuate [17]. The period of these oscillations ranged between 32 and $107 \mathrm{~min}$. On the other hand, in 3 pancreatectomized dogs, extrapan- 


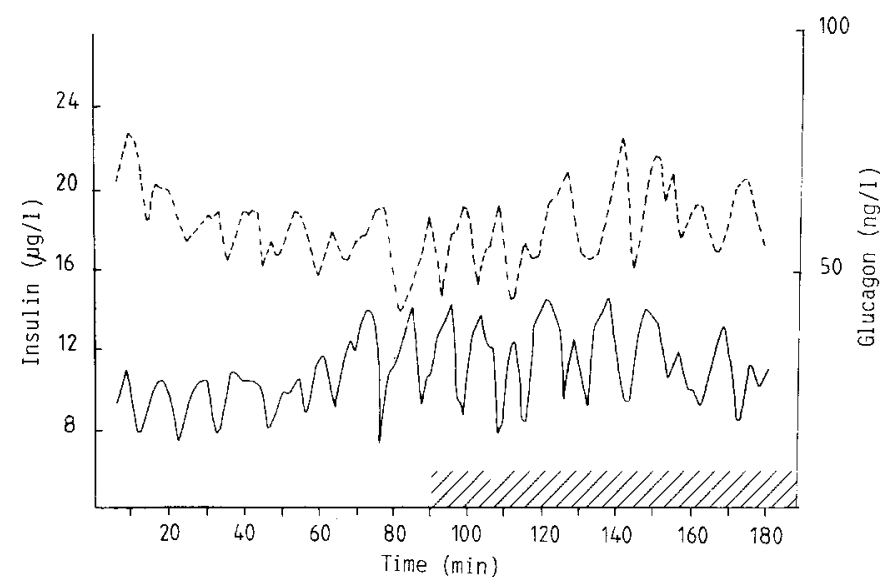

Fig. 2. Comparison of insulin and glucagon cycles in the isolated perfused canine pancreas. Representative cycles of insulin (solid line) and glucagon (broken line) from a single pancreas before and after combined blockade by atropine, propranolol, and dibenziline. Combined blockade (shaded area) was without effect on cycle frequency or the ratio of peak amplitude to the total secretion during each cycle. The shapes of the glucagon curves are exaggerated by the scale which is relative to insulin. From Stagner et al. [24]. Reproduced with permission of the copyright holder

creatic glucagon and somatostatin appeared to be secreted in nonperiodic, randomly occurring pulses [17].

Oscillations in blood glucose and insulin levels were also studied during hyperglycaemia. In 1974, Ookthens et al. [18] reported that, in dogs, plasma glucose and insulin displayed regular, synchronous oscillations with a period of about $50 \mathrm{~min}$ for up to $10 \mathrm{~h}$ of constant glucose infusion. In another study, constant infusion of glucose into conscious dogs induced oscillations in plasma glucose concentration with an even longer period averaging $112 \mathrm{~min}$ [19]. They were accompanied by similar oscillations in plasma insulin levels, lagging $22 \mathrm{~min}$ behind glucose cycles. However, a further study showed that clamping plasma glucose concentration at a similar level (by adjusting the infusion rate) did not obliterate but rather augmented the oscillations in plasma insulin levels [20].

In overnight fasted rhesus monkeys, Goodner et al. [4] reported the occurrence of synchronous, regular oscillations in the peripheral plasma concentrations of glucose, insulin and glucagon. The oscillations displayed a mean period of $9 \mathrm{~min}$, and the amplitudes for insulin and glucagon were ten- and five-fold greater than for glucose. Insulin cycled in, and glucagon out, of phase with glucose. Subsequent measurements further showed that plasma C-peptide levels were oscillating in synchrony with glucose [21]. Recently, direct sampling in the portal vein of two baboons confirmed that regular insulin cycles (period 9-10 min) were consistently followed by glucagon pulses $4-5$ min later [16]. These latter experiments also revealed that peaks in the profile of pancreatic polypeptide occurred in synchrony with either insulin or glucagon, whereas the fluctuations of somatostatin were erratic, without significant periodicity.
Further studies were performed in the rhesus monkeys to gain insight into the mechanisms underlying these oscillations. Neither the period, nor the relative amplitude of the oscillations in plasma levels of insulin and glucose were affected by muscarinic or $\alpha$ - and $\beta$ adrenergic blockade, in spite of changes in mean absolute levels of plasma insulin [22]. General anaesthesia with pentobarbital similarly failed to eliminate the oscillations. Taken together these observations reduced the likelihood that the oscillations originate from a pacemaker in the central nervous system [22]. In 12 rhesus monkeys, both relative and absolute amplitudes of insulin oscillations increased after a mixed meal, but the period of oscillations did not change [23].

Conversely, food deprivation for up to $88 \mathrm{~h}$ decreased amplitude and regularity of the oscillations, but, again, did not affect the underlying periodicity of insulin, glucose and glucagon cycles [23].

\section{Pulsatile insulin and glucagon secretion in vitro}

\section{From the isolated perfused pancreas}

As illustrated by Figure 2, sustained oscillations in the release of insulin, glucagon and somatostatin from the isolated canine pancreas perfused at a constant concentration of glucose were convincingly demonstrated by Stagner and Samols [24, 25]. For insulin cycles a period of about 10 min was estimated from raw data [24], but a shorter period of $7.4 \mathrm{~min}$ was computed by mathematical analysis of the results [25]. Insulin and somatostatin cycles were in phase, but glucagon cycles were less regular, shorter and not consistently $90^{\circ}$ out of phase with insulin cycles [24]. Similar oscillations in insulin release were observed when the two lobes of the pancreas (respectively rich in glucagon or in pancreatic polypeptide cells) were perfused separately [26]. The period of insulin cycles was unaffected by the concentration of glucose $(5$ or $11 \mathrm{mmol} / \mathrm{l})$ in the medium perfusing the whole pancreas $[24,25]$ or the lobe rich in glucagon cells [26], but became shorter when a high glucose medium was used to perfuse the lobe rich in pancreatic polypeptide cells [26].

Persistence of the pulsatility of insulin release in the isolated pancreas suggested that it depends on a pacemaker system present in the gland itself. Several approaches were thus followed to determine whether insulin oscillations are controlled by the intrapancreatic nervous system. First, insulin cycles were disrupted by infusions of various neurotransmitters [24]. This observation means that the mechanisms controlling the oscillations can be overriden by neural influences, possibly acting directly on B cells. Second, and as illustrated by Figure 2, insulin cycles persisted unabated during infusion of atropine, propranolol, and dibenzyline [24]. This shows that muscarinic and adrenergic receptors play no major role in the generation of these oscil- 
lations. Third, insulin cycles were altered by tetrodotoxin, a blocker of $\mathrm{Na}$ channels [25]. Though this effect may have resulted from the expected nerve blockade, other possibilities cannot be ruled out. Indeed, tetrodotoxin is known to inhibit glucose-induced somatostatin release from the perfused canine pancreas [27] and to alter glucose-induced electrical activity in mouse B cells $[28,29]$. Fourth, the period of insulin cycles was decreased by infusion of postsynaptic nicotinic receptor antagonists [30,31], which are not known to exert direct effects on B cells. These observations are in keeping with the hypothesis that the network of pancreatic ganglia and interconnecting nerves has a role in the control of insulin cycles. However, an alternative interpretation would be that these pharmacological manipulations release a substance or substances (peptidergic?) that override the pacemaker control system and cause the observed increase in insulin secretion. Coordination by a network of ganglia and nerves would also imply the presence of connections across the plane of connective tissue separating the two pancreatic lobes of distinct embryological origin [32, 33], or the existence of two separate but similar pacemakers. To the best of our knowledge, sustained fluctuations of insulin release by the perfused rat or mouse pancreas have not been described. It has only been reported that inhibition of glucose-stimulated insulin release by clonidine disclosed an apparently rhythmic pattern of secretion for a short period of time [34].

\section{From isolated islets}

There have been only few attempts to determine whether insulin release by isolated islets is pulsatile or not. A pulsatile pattern was described by using a system in which a single mouse islet was attached to the tip of a micropipet by suction, and dipped into successive small cups $[35,36]$. However, this system resulted in the release of enormous amounts of insulin $(5-25 \mu \mathrm{U} / 15 \mathrm{~s}$ for a medium-size islet). This is incomparably more than the rate of insulin release measured in any system of perifusion using groups of islets, or even single large islets [37]. Moreover, the experiments with the dipping technique were performed at $30-31{ }^{\circ} \mathrm{C}$. Since the B-cell membrane is likely to be persistently depolarised at that temperature [38], the attempts to correlate the alleged periodicity of insulin release with oscillations of B-cell-membrane potential [36] are not grounded.

It has also been claimed that insulin release by single mouse islets is pulsatile with a similar periodicity to phases of electrical activity simultaneously recorded in B cells [39]. While it is acknowledged that such experiments are difficult to perform, it is obvious that a more detailed and complete account than an abstract is required to carry conviction. In particular, it is puzzling that insulin release was found to stop after each phase of electrical activity, whereas, in another study, release
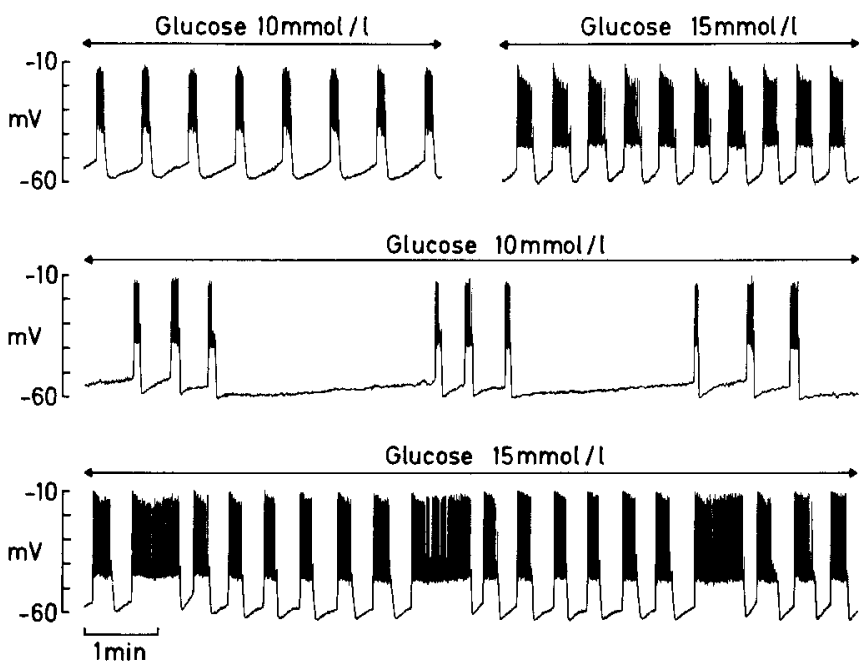

Fig.3. Effects of 10 and $15 \mathrm{mmol} / 1$ glucose on the membrane potential of mouse $B$ cells. The four records were obtained in different mice

continued for quite a while after electrical activity had been stopped by a decrease in glucose concentration [40]. A last short communication reported on the periodicity of insulin release from individual islets of obese rats [41]. These measurements were made just after the change from a glucose-free medium to a medium containing $28 \mathrm{mmol} / 1$ glucose. The sampling period ( $5 \mathrm{~min}$ ) thus corresponds to the first phase of insulin release and not to steady state release. Furthermore, it is rather surprising that, in these experiments [41], insulin release was stimulated without delay, in spite of the long (45 min) initial period of perifusion with a glucose-free medium. Finally, glucose-stimulated insulin release by groups of perifused rabbit islets was reported to display an irregular, "spiky" pattern, that did not characterise insulin release by groups of rat islets [42]. This peculiarity has neither been confirmed, nor further analysed.

In summary, conclusive evidence for or against pulsatility of insulin release by isolated islets is still lacking. Demonstration of its presence (or absence) also requires precise characterisation of the immunoassay and careful mathematical analysis of the data, as has been done in in vivo studies.

\section{Oscillations of B-cell-membrane potential}

It is doubtful that classical methods will ever be able to demonstrate whether insulin release from a single $B$ cell is pulsatile or not. This might perhaps become possible by monitoring changes in membrane capacitance [43], if these latter prove to reflect adequately exocytosis-endocytosis processes.

On the other hand, it has long been recognised that the membrane potential of mouse $B$ cells oscillates rhythmically during stimulation by glucose concentrations which induce insulin release $[44,45]$. These oscil- 
lations (Fig.3) are characterised by phases of depolarisation (slow waves) with bursts of spikes superimposed on the plateau, alternating with phases of silent repolarisation (intervals). The ionic currents underlying these electrical events, and the mechanisms whereby glucose controls them are not yet fully understood (for a review see 46). Nevertheless, strong evidence supports a causal role of these phenomena in glucose-induced insulin release.

In many B cells, slow waves and intervals remain very regular as long as the concentration of glucose remains constant (Fig. 3, upper records). However, they can vary in frequency, amplitude or duration from islet to islet. Smaller differences may also exist between B cells within the same islet, probably because not all B cells of the islet are (permanently) electrically coupled $[47,48]$. In certain cells, slow waves and intervals themselves also display fluctuations in their duration. These fluctuations were first recognised during steady-state stimulation with a mixture of glucose and leucine [49]. Thereafter, it became evident that they are sometimes present during stimulation with glucose alone [50, 51]. Figure 3 shows examples of these fluctuations in two B cells stimulated by 10 or $15 \mathrm{mmol} / 1$ glucose.

Studies of these oscillations is fraught with the difficulty that they may spontaneously disappear with time. From retrospective analysis of the recordings, it appeared that their incidence was higher ( 45 vs $20 \%$ of $B$ cells) and their period slightly longer (3.9 vs $3.4 \mathrm{~min}$ ) in the presence of $15 \mathrm{vs} 10 \mathrm{mmol} / 1$ glucose [50]. Their presence also seemed to be unrelated to islet size or to the season, and did not require connection of the islet to extrainsular tissue [51]. Attempts to disrupt these oscillations showed that they were insensitive to blockade of muscarinic, or $\alpha$ - and $\beta$-adrenergic receptors [50]. Preliminary experiments also suggest that they are unaffected by blockade of opiate and nicotinic receptors (J.C. Henquin and W. Schmeer, unpublished data). A reversible suppression of these oscillations could only be produced by increasing cAMP levels in B cells. Thus, upon addition of a low concentration of forskolin, a potent activator of the adenylate cyclase, the electrical activity became very regular, with slow waves and intervals of constant duration [52]. In summary, the mechanisms and significance of the slow fluctuations of glucose-induced electrical activity present in certain B cells, and their possible relationship with pulsatile insulin secretion are still unknown.

\section{Nature of the pacemaker}

It is now generally agreed that the fluctuations in plasma insulin levels measured in vivo reflect similar fluctuations of insulin release, and that the pacemaker of these oscillations is localised in the pancreas itself. It might be premature, however, to dismiss a possible modulatory role of extrapancreatic factors. Thus, the period of insulin cycles measured in the portal vein of conscious dogs averaged $12 \mathrm{~min}$ [16], as compared to $7.6 \mathrm{~min}$ in the isolated canine pancreas [25].

There is no experimental evidence that paracrine influences play a role in the generation of insulin cycles, but no decisive argument permits one to exclude it formally either. As already emphasised, the hypothesis currently in favour is that the ensemble of connected ganglia and associated nerves of the pancreas synchronizes islet hormone oscillations [30, 31]. Whether this synchronization is exerted directly on B cells or employs less direct pathways is unknown. Final proof that pulsatility of insulin release is under neural control may require its blockade by a specific antagonist that is without direct effect on islets freed from all neural connections.

An alternative possibility is that pulsatility of release is an intrinsic property of each islet or of each B cell. Fluctuations measured in portal or peripheral blood could thus be a beat oscillation of secretory events occurring with a more rapid, but not necessarily synchronous periodicity in all islets, and damped by diffusion and dilution [50, 53]. Strong support for this possibility was recently provided by a study performed in dogs with intrasplenic islet autografts [54]. These animals exhibited oscillations in basal portal insulin levels which were similar to those measured in control dogs. Obviously, both confirmation of this new observation and experiments using single isolated islets are necessary to assess this hypothesis. In this perspective a prerequisite is the demonstration that oscillations in portal insulin levels exist (in vivo and in vitro) in the species from which the islets are isolated. It would be unwise to assume, a priori, that they must exist and have the same periodicity in every species as has been reported in man, monkeys or dogs.

\section{Comparative effects of continuous and pulsatile hormone delivery}

In vivo studies in fasted rhesus monkeys demonstrated that the oscillations in the concentration of plasma glucose reflect fluctuations in hepatic glucose production, and that these fluctuations were synchronous with the oscillations in insulin and glucagon concentrations [55]. This synchrony suggests that hepatic glucose metabolism is entrained to the islet cycle. Though the physiologic and physiopathologic significance of these observations remains to be established, several studies were performed to assess the possible biologic advantages of cyclic delivery of pancreatic hormones.

\section{Insulin}

Matthews et al. [56] were the first to suggest that pulsatile insulin might have greater biologic effects than continuous delivery: in six normal subjects in whom 
pancreatic insulin output was suppressed by somatostatin, they showed that intermittently delivered insulin ( 2 min pulses separated by gaps of $11 \mathrm{~min}$ ) had greater hypoglycaemic effects than the same amount of insulin delivered continuously. Such differences were significant only after $7 \mathrm{~h}$ of insulin infusion. A recent study by Schmitz et al. [57] confirmed these findings: in 8 healthy subjects soluble insulin was given intravenously either at a constant rate or in identical amounts in pulses of 1.5 to 2.25 min separated by intervals of 10.5 to $9.75 \mathrm{~min}$. The amounts of insulin infused completely inhibited endogenous glucose production, as estimated by the $\left[3-{ }^{3} \mathrm{H}\right]$ glucose infusion technique. Glucose uptake, expressed as metabolic clearance rate (MCR), was significantly increased as compared with continuous administration. Here again the superior efficacy of pulsatile insulin delivery in glucose uptake was not consistently found until after $210 \mathrm{~min}$ of insulin administration. In experiments of shorter duration, as those of Verdin et al. [58] or Paolisso et al. [59], such superior efficacy of pulsatile insulin was not found.

Several factors may be critical for the demonstration of the superior efficacy of pulsatile insulin. First, insulin is infused in a peripheral vein and not in the portal vein where the largest spontaneous fluctuations occur. Second, the greater efficacy could be lost if insulin pulses are not accompanied with glucagon pulses or are asynchronous with endogenous glucagon cycles. Third, and as illustrated by Figure 4, slight hyperglucagonaemia, in the range of about $200 \mathrm{ng} \cdot 1^{-1}$ is sufficient to abolish the higher efficacy of pulsatile insulin [60].

In vitro studies by Komjati et al. [61] have confirmed the superior efficacy of pulsatile versus continuous insulin exposure on the isolated perfused rat liver. In this system, insulin $\left(100 \mathrm{mU} \cdot \mathrm{l}^{-1}\right)$ given continuously and intermittently ( $3 \mathrm{~min}$ on/off intervals) inhibited glucagon-stimulated hepatic glucose production to the same extent (37.4 and $41.1 \%$ respectively). Doubling the off-period to $6 \mathrm{~min}$, and thereby reducing the total insulin dose to $33 \%$, did not significantly diminish the suppressive effect of insulin on glucagon-stimulated hepatic glucose release $(34.6 \%)$.

It is also possible that the fluctuations in plasma insulin concentration are of importance for the regulation of islet-cell function itself. In fasted anaesthetized rats [62], the rise in plasma insulin levels induced by an intravenous glucose challenge was attenuated by previous intraportal infusion of insulin in a continuous mode, but was augmented if the same amount of insulin had been given in pulses. In normal human subjects (Paolisso et al., submitted for publication), whose blood glucose was maintained constant, insulin infusion resulted in a significant decline in basal plasma glucagon and C-peptide, and in a clearcut decrease in the glucagon response to subsequent arginine stimulation. All these changes were more pronounced when identical amounts of insulin were delivered in a pulsa- tile rather than in a continuous manner. Obviously these in vivo studies do not indicate the site of islet-cell control by insulin. It could well be intrainsular for the A-cell [63] and extrapancreatic (neurally mediated) for the $B$ cell [64].

\section{Glucagon}

In contrast to insulin, the functional consequences of pulsatile glucagon delivery have been less investigated. Weigle et al. [65] have shown that administering glucagon as a series of brief pulses to perifused rat hepatocytes resulted in the production of a greater total amount of glucose than was obtained when the same amount of glucagon was administered as a continuous infusion. The response augmentation by pulsatile glucagon administration was interpreted as a delayed relaxation in hepatocyte glucose production after termination of each hormone pulse. Using a model based on the waveform of the hepatocyte response to a transient glucagon stimulus, the same authors [66] demonstrated that the time constant for response decay was an important determinant of the relative efficacy of continuous and intermittent hormone delivery. In further studies using the same in vitro system, Weigle and Goodner [67] reported that the enhancement of hepatic glucose production by glucagon-pulses is a frequencydependent phenomenon and that hepatic glucose production is optimised for interpulse intervals of 10-20 min, a period close to the physiological secretory period of $10 \mathrm{~min}$ observed in non-human primates $[4,22,23]$ and of $14-20 \mathrm{~min}$ reported in humans [10-12]. Recently, Komjati et al. [61] have investigated the effect of pulsatile versus continuous glucagon exposure on glucose production from the isolated perfused rat liver. They observed that continuous exposure to glucagon $\left(35 \mathrm{pmol} \cdot \mathrm{1}^{-1}\right)$ induced a two-fold increase in hepatic glucose production, while intermittent exposure ( $3 \mathrm{~min}$ on/off intervals; total dose 50\%) to the same glucagon concentration elicited an almost identical increase in hepatic glucose output. Therefore, all these in vitro studies concur to demonstrate that pulsatile delivery of glucagon is more efficient that continuous exposure to stimulate hepatic glucose production. The only study on the respective effects of continuous and intermittent glucagon infusion in vivo performed in man has been by Paolisso et al. [68]. Six male volunteers were submitted to a $260 \mathrm{~min}$ glucosecontrolled glucose intravenous administration using the Biostator. The endogenous secretion of the pancreatic hormones was inhibited by somatostatin. Basal insulin secretion was replaced by a continuous insulin infusion resulting in steady plasma insulin levels averaging 8-11 $\mathrm{mU} / 1$. Glucagon was infused intravenously in two conditions at random: either continuously or intermittently with a switching on/off length of $2 / 11 \mathrm{~min}$. During continuous glucagon infusion, glucagon plasma levels averaged $189 \pm 38 \mathrm{ng} / \mathrm{l}$; during pul- 


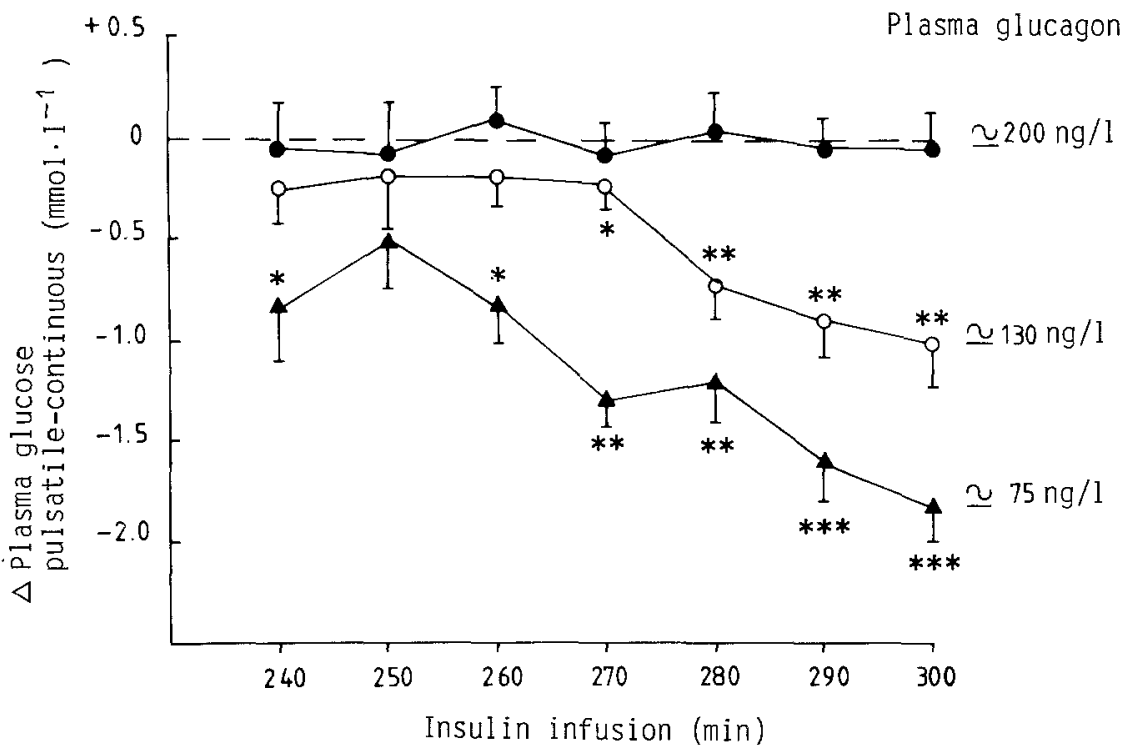

Fig. 4. Differences $(\Delta)$ in plasma glucose concentration between pulsatile and continuous modes of insulin delivery. The same six Type 1 diabetic patients were investigated at three different plasma glucagon levels, as indicated. During the fifth hour of infusions, there was no difference between the two modes of insulin administration when somatostatin-suppressed endogenous glucagon was replaced by exogenous infusion maintaining circulating glucagon levels at about $200 \mathrm{ng} / \mathrm{l}$. The superior efficacy of pulsatile over continuous insulin infusion appears for glucagon levels averaging $130 \mathrm{ng} / 1$ and is more marked when glucagon levels are around $75 \mathrm{ng} / \mathrm{l}$. From Paolisso et al. [60]. Reproduced with permission of the copyright holder

satile infusion they varied between 95 and $501 \mathrm{ng} / 1$. When compared with continuous delivery, pulsatile glucagon infusion: (a) initially induced a similar increase in endogenous (hepatic) glucose production and blood glucose, (b) did not prevent the so-called "evanescent" effect of glucagon on blood glucose, and (c) after $3 \mathrm{~h}$ tended to reduce rather than increase hepatic glucose production [68]. The reasons for the discrepancy between in vitro and in vivo experiments using glucagon are still unclear. The relatively high circulating glucagon levels achieved and the characteristics of glucagon kinetics in vivo in man are likely to be involved. We have speculated [68] that in the conditions achieved in our experimental protocol in vivo, the hepatocytes remain exposed to circulating glucagon concentrations which, despite the intermittent mode of administration, may still be high enough to desensitise the hepatocytes even more than during continuous administration of the hormone. As reviewed by Rodbell [69], the intimate mechanism of such a desensitisation, already reported in various systems $[70,71]$, is still not understood.

\section{Pulsatility of insulin delivery and diabetes management}

\section{In Type 1 (insulin-dependent) diabetes}

Bratusch-Marrain et al. [72] recently compared the effects of continuous and pulsatile insulin administration on hepatic glucose production-utilisation in Type 1 diabetic patients submitted to a euglycaemic insulin clamp procedure. The total amount of insulin infused in the pulsatile manner was $40 \%$ less than when it was infused continuously.

Despite this reduction, insulin given in the pulsatile manner was equally potent in reducing hepatic glucose production and stimulating glucose utilisation. The authors suggested that intravenous pulsatile adminis- tration of insulin might reduce systemic hyperinsulinaemia and, in the long run, attenuate insulin resistance by reversing down-regulation of insulin receptors. Paolisso et al. [60] confirmed the greater efficacy of pulsatile insulin in reducing plasma glucose in Type 1 diabetic patients (Fig.4) but demonstrated that this effect was critically dependent on plasma glucagon levels: completely absent at plasma glucagon concentrations averaging $200 \mathrm{ng} / \mathrm{l}$, it was observed at glucagon levels averaging $130 \mathrm{ng} / \mathrm{l}$; and occurred earlier, and was more pronounced when plasma glucagon concentrations were about $75 \mathrm{ng} / 1$. Another beneficial effect of pulsatile insulin administration in diabetic patients could be a reduction of hyperglucagonaemia, a universally found feature of diabetes [73]. Thus, the exaggerated response of the pancreatic A-cell to intravenous arginine observed in patients with diabetes was significantly reduced when small amounts of insulin were delivered in a pulsatile manner while identical amounts delivered continuously were without significant effect (Paolisso et al., submitted for publication). However, attempts to achieve better control of Type 1 diabetes by pulsed insulin given subcutaneously have failed. In the study performed by Levy-Marchal et al. [74] in 6 Type 1 diabetic patients, overnight metabolic control was similar when a given amount of insulin was delivered subcutaneously either in a continuous manner or intermittently as pulses spaced at 30-, 60- and 120-min intervals. Under those conditions, however, no oscillations in plasma insulin were achieved. In contrast to what has been reported above with intravenous insulin administration [72], a reduction of the dose of insulin infused subcutaneously was not compensated for by the intermittent administration of the hormone [75].

\section{In Type 2 (non-insulin-dependent) diabetes}

In Type 2 diabetic patients the short-term oscillations of plasma insulin are more rapid and generally less 
regular than in normal subjects [13]. These brief, irregular oscillations with a mean period of $8.8 \mathrm{~min}$ are superimposed on longer time fluctuations $(>30 \mathrm{~min})$. The importance of the deviation of these oscillations from the normal pattern in the pathophysiology of Type 2 diabetes is entirely unknown. It is possible that such disturbances of the normal oscillatory secretory pattern of insulin contribute to the hyperglucagonaemia of Type 2 diabetes, a classically recognised but still poorly understood phenomenon [73]. In such patients, glibenclamide increased plasma insulin levels but failed to restore normal insulin pulsatility [76].

\section{Conclusions}

Numerous studies performed in animals (dog, baboon, rhesus monkey) and in man have depicted the existence of peripheral plasma insulin and glucagon oscillations. Such oscillations were also reported in the portal blood of dogs and monkeys. The frequency of these oscillations is remarkably stable but their amplitude is increased after a meal and decreased by food deprivation. Sustained oscillations in the release of insulin, glucagon and somatostatin from the isolated perfused canine pancreas have been repeatedly reported. Systematic experiments have shown that these oscillations are not affected by exposure to various pharmacological compounds including atropine, propranolol, or dibenziline. The suggestion has been made that the pulsatility of pancreatic hormone release depends on a pacemaker system present in the gland itself. In contrast, conclusive evidence for or against pulsatility of hormone release by isolated islets is still lacking. Similarly, the possible relationship of the slow fluctuations of glucose-induced electrical activity present in certain $B$ cells with pulsatile insulin secretion is still unknown.

Several in vivo and in vitro studies have shown that pulsatile insulin has greater biological effects than continuous delivery. However, various factors are critical for the demonstration of the superior efficacy of pulsatile insulin; these include duration of hormonal exposure, circulating levels of insulin achieved and, most importantly, coexisting concentrations of circulating glucagon. In fact, slight hyperglucagonaemia (in the range of $200 \mathrm{ng} \cdot \mathrm{I}^{-1}$ ) is sufficient to abolish the higher efficacy of pulsatile insulin in man. In vitro studies have shown that pulsatile delivery of glucagon is more efficient than continuous exposure to stimulate hepatic glucose protection. Until now, attempts to confirm such effects in man have failed. Finally, recent reports have indicated that pulsatile intravenous insulin infusion in diabetic patients is more efficient than continuous delivery in reducing hepatic glucose production, stimulating glucose utilisation and inhibiting A-cell glucagon release. In contrast, attempts to achieve better control of Type 1 diabetes by pulsed insulin given subcutaneously have failed. In Type 2 diabetic patients, preliminary data have shown that the short-term oscillations of plasma insulin are more rapid and generally less regular than in normal subjects; it has been suggested that such disturbances of the normal oscillatory secretory pattern of insulin may contribute to the hyperglucagonaemia of Type 2 diabetes. Until now, attempts to restore normal insulin pulsatility in these patients have failed.

Acknowledgments. G. Paolisso was on leave from the University of Naples (Italy). J.C. Henquin is "Maitre de Recherches" of the Fonds National de la Recherche Scientifique, Brussels, Belgium. We acknowledge the expert secretarial help of E. Vaessen-Petit. The authors' work referred to in this review was supported by the Fonds National de la Recherche Scientifique (Belgium), the Fonds de la Recherche Scientifique Médicale (Belgium), a research grant of the University of Liège (Belgium), and by the Deutsche Forschungsgemeinschaft, SBF 38 and 246 (FRG).

\section{References}

1. Krieger DT (1979) Endocrine rhythms. Raven Press, New York

2. Borges JLC, Blizzard RM, Evans WS, Furlanetto R, Rogol AD, Kaiser DL, Rivier J, Vale W, Thorner MO (1984) Stimulation of growth hormone $(\mathrm{GH})$ and somatomedin $\mathrm{C}$ in idiopathic GH-deficient subjects by intermittent pulsatile administration of synthetic human pancreatic tumor GH-releasing factor. J Clin Endocrinol Metab 59: 1-6

3. Belchetz PE, Plat TM, Nakai Y, Keogh EJ, Knobil E (1978) Hypophyseal responses to continuous and intermittent delivery of hypothalamic gonadotropin-releasing hormone. Science 202: $631-633$

4. Goodner CJ, Walike BC, Koerker DJ, Ensinck JE, Brown AC, Chideckel EW, Palmer J, Kalnasy L (1977) Insulin, glucagon, and glucose exhibit synchronous sustained oscillations in fasting monkeys. Science 195: 177-179

5. Hansen K (1923) Investigations on the blood sugar in man: conditions of oscillations, rise and distribution. Acta Med Scand [Suppl 4] 1-221

6. Anderson GE, Hillman RW, Van Elk IFA, Perfetto AJ (1956) Postabsorptive ondulations and oscillations in blood glucose. Am J Clin Nutr 4: 673-686

7. Iberall A, Ehrenberg M, Cardon S, Simenhoff M (1968) High frequency blood glucose oscillations in man. Metabolism 17: 1119-1121

8. Deckert T, Ege $P(1970)$ Variations in plasma glucose in normal subjects and diabetics in the fasting state. Acta Med Scand 187: 331-336

9. Lang DA, Matthews DR, Peto PJ, Turner RC (1979) Cyclic oscillations of basal plasma glucose and insulin concentrations in human beings. N Engl J Med 301: 1023-1027

10. Lang DA, Matthews DR, Burnett M, Ward GM, Turner RC (1982) Pulsatile, synchronous basal insulin and glucagon secretion in man. Diabetes 31: 22-26

11. Hansen BC, Jen K-L C, Belbez-Pek S, Wolfe RA (1982) Rapid oscillations in plasma insulin, glucagon and glucose in obese and normal weight humans. J Clin Endocrinol Metab 54: 785-792

12. Matthews DR, Lang DA, Burnett MA, Turner RC (1983) Control of pulsatile insulin secretion in man. Diabetologia 24: 231-237

13. Lang DA, Matthews DR, Burnett M, Turner RC (1981) Brief, irregular oscillations of basal plasma insulin and glucose concentrations in diabetic man. Diabetes 30: 435-439

14. Simon C, Brandenberger G, Follenius M (1987) Ultradian oscillations of plasma glucose, insulin and C-peptide in man under continuous enteral nutrition. J Clin Endocrinol Metab 64: $669-674$ 
15. Anderson GE, Kologlu Y, Papadopoulos C (1967) Fluctuations in postabsorptive blood glucose in relation to insulin release. Metabolism 16: 586-596

16. Jaspan JB, Lever E, Polonsky KS, Van Cauter E (1986) In vivo pulsatility of pancreatic islet peptides. Am J Physiol 251: E215-E226

17. Sirek A, Vaitkus P, Norwich KH, Sirek OV, Unger RH, Harris V (1985) Secretory patterns of glucoregulatory hormones in prehepatic circulation of dogs. Am J Physiol 249: E34-E42

18. Ookhtens M, Marsh DJ, Smith SW, Bergman RN, Yates FE (1974) Fluctuations of plasma glucose and insulin in conscious dogs receiving glucose infusions. Am J Physiol 226 (4): 910-919

19. Bowden CR, Bergman RN, Marsh DJ (1980) Cause of glucose oscillations during glucose infusion: periodic variation in glucose uptake. Am J Physiol 238: E395-E407

20. Marsh BD, Marsh DJ, Bergman RN (1986) Oscillations enhance the efficiency and stability of glucose disposal. Am J Physiol 250: E576-E582

21. Koerker DJ, Goodner CJ, Hansen BW, Brown AC, Rubenstein $\mathrm{AH}$ (1978) Synchronous sustained oscillations of C-peptide and insulin in the plasma of fasting monkeys. Endocrinology 102: $1649-1652$

22. Hansen BC, Pek S, Koerker DJ, Goodner CJ, Wolfe RA, Schielke GP (1981) Neural influences on oscillations in basal plasma levels of insulin in monkeys. Am J Physiol 240: E5-E11

23. Hansen BC, Jen K-LC, Koerker DJ, Goodner CJ, Wolfe RA (1982) Influence of nutritional state on periodicity in plasma insulin levels in monkeys. Am J Physiol 242: R255-R260

24. Stagner JI, Samols E, Weir GC (1980) Sustained oscillations of insulin, glucagon, and somatostatin from the isolated canine pancreas during exposure to a constant glucose concentration. J Clin Invest 65: 939-942

25. Stagner JI, Samols E (1985) Perturbation of insulin oscillations by nerve blockade in the in vitro canine pancreas. Am J Physiol 248: E516-E521

26. Stagner J, Samols E (1982) Disparate cyclic hormone release between the dorsal and ventral lobes of the in vitro canine pancreas. Proceedings of the 64th Meeting of the Endocrine Society, p361 (Abstract)

27. Hermansen K (1980) The role of sodium in somatostatin secretion: evidence for the involvement of $\mathrm{Na}$ channels in the release mechanism. Endocrinology 106: 1843-1847

28. Meissner HP, Preissler M (1980) Ionic mechanisms of the glucose-induced membrane potential changes in B cells. Horm Metab Res [Suppl] 10: 91-99

29. Tarvin JT, Pace CS (1981) Glucose-induced electrical activity in the pancreatic B cell: effect of veratridine. Am J Physiol 240: $\mathrm{C} 127-\mathrm{C} 134$

30. Stagner JI, Samols E (1985) Role of intrapancreatic ganglia in regulation of periodic insular secretions. Am J Physiol 248: E522-E530

31. Stagner JI, Samols E (1986) Modulation of insulin secretion by pancreatic ganglionic nicotinic receptors. Diabetes 35: 849-854

32. Malaisse-Lagae F, Stefan Y, Cox J, Perrelet A, Orci L (1979) Identification of a lobe in the adult human pancreas rich in pancreatic polypeptide. Diabetologia 17: 361-365

33. Rahier J, Wallon J, Gepts W, Haot J (1979) Localization of pancreatic polypeptide cells in a limited lobe of the human neonate pancreas: remnant of the ventral primordium? Cell Tissue Res 200: $359-366$

34. Leclercq-Meyer V, Herchuelz A, Valverde I, Couturier E, Marchand J, Malaisse WJ (1980) Mode of action of clonidine upon islet function. Dissociated effects upon the time course and magnitude of insulin release. Diabetes 29: 193-200

35. Bessman SP, Beigelman PM, Thomas LJ (1973) The periodicity of insulin secretion by islet of Langerhans shown by a new apparatus. Biochem Med 7:97-102

36. Beigelman PM, Thomas LJ, Shu MJ, Bessman SP (1976) Insulin from individual islets of Langerhans. Effect of glucose in varying concentrations. J Physiol (Paris) 72: 721-728
37. Panten U, Ishida H, Schauder P, Frerichs H, Hasselblatt A (1977) Versatile microperifusion system. Anal Biochem 82: 317-326

38. Atwater I, Goncalves A, Herchuelz A, Lebrun P, Malaisse WJ, Rojas E, Scott A (1984) Cooling dissociates glucose-induced insulin release from electrical activity and cation fluxes in rodent pancreatic islets. J Physiol 348: 615-627

39. Atwater I, Rojas E, Scott A (1979) Simultaneous measurement of insulin release and electrical activity from single microdissected mouse islets of Langerhans. J Physiol 291: 57P (Abstract)

40. Scott AM, Atwater I, Rojas E (1981) A method for the simultaneous measurement of insulin release and B cell membrane potential in single mouse islets of Langerhans. Diabetologia 21 : $470-475$

41. Hayek A (1981) Preservation of insulin release periodicity from individual islets of obese Zucker rats. Horm Metab Res 13: $119-120$

42. Garcia-Hermida O, Gomez-Acebo J (1974) A different pattern of insulin release in the perifused islets of the rabbit. Biochem Biophys Res Commun 57: 209-215

43. Neher E, Marty A (1982) Discrete changes of cell membrane capacitance observed under conditions of enhanced secretion in bovine adrenal chromaffin cells. Proc Natl Acad Sci USA 79: 6712-6716

44. Dean PM, Matthews EK (1970) Glucose-induced electrical activity in pancreatic islet cells. J Physiol 210: 255-264

45. Meissner HP, Schmelz H (1974) Membrane potential of beta cells in pancreatic islets. Pflügers Arch 351: 195-206

46. Henquin JC, Meissner HP (1984) Significance of ionic fluxes and changes in membrane potential for stimulus-secretion coupling in pancreatic B-cells. Experientia 40: 1043-1052

47. Meissner HP (1976) Electrophysiological evidence for coupling between B cells of pancreatic islets. Nature 262: 502-504

48. Meda P, Atwater I, Goncalves A, Bangham A, Orci L, Rojas E (1984) The topography of electrical synchrony among B cells in the mouse islet of Langerhans. Quart J Exp Physiol 69: 719-735

49. Henquin JC, Meissner HP (1981) Effects of amino acids on membrane potential and ${ }^{86} \mathrm{Rb}^{+}$fluxes in pancreatic B cells. Am $\mathrm{J}$ Physiol 240: E245-E252

50. Henquin JC, Meissner HP, Schmeer W (1982) Cyclic variations of glucose-induced electrical activity in pancreatic B cells. Pflügers Arch 393: 322-327

51. Cook DL (1983) Isolated islets of Langerhans have slow oscillations of electrical activity. Metabolism 32: 681-685

52. Henquin JC, Schmeer W, Nenquin M, Meissner HP (1984) Forskolin supresses the slow cyclic variations of glucose-induced electrical activity in pancreatic B cells. Biochem Biophys Res Commun 120: 797-803

53. De Haen C, Gorray KC, Howland HC (1981) A model for oscillatory and biphasic insulin secretion. Diabetes 30: 114A (Abstract)

54. Kakizaki K, Basadonna G, Merrell RC (1986) Neural regulation of hererotopic islets of Langerhans. Surgery 100: 997-1002

55. Goodner CJ, Hom FG, Koerker DJ (1982) Hepatic glucose production oscillates in synchrony with the islet secretory cycle in fasting rhesus monkeys. Science 215: 1257-1260

56. Matthews DR, Naylor BA, Jones RG, Ward GM, Turner RC (1983) Pulsatile insulin has greater hypoglycemic effect than continuous delivery. Diabetes 32: 617-621

57. Schmitz O, Ainfred J, Hother Nielsen O, Beck-Nielsen $H$, Ørskov H (1986) Glucose uptake and pulsatile insulin infusion: euglycaemic clamp and $3-{ }^{3} \mathrm{H}$ glucose studies in healthy subjects. Acta Endocrinol (Copenh) 113: 559-563

58. Verdin E, Castillo M, Luyckx AS, Lefèbvre PJ (1984) Similar metabolic effects of pulsatile versus continuous human insulin delivery during euglycemic, hyperinsulinemic glucose clamp in normal man. Diabetes 33: 1169-1174

59. Paolisso G, Scheen AJ, Verdin E, Luyckx AS, Lefèbvre PJ (1986) Insulin oscillations per se do not affect glucose turnover parameters in normal man. J Clin Endocrinol Metab 63: 520-525

60. Paolisso G, Sgambato S, Passariello N, Scheen AJ, D'Onofrio F, 
Lefèbvre PJ (1987) Greater efficacy of pulsatile insulin in type 1 diabetics critically depends on plasma glucagon levels. Diabetes 36: $566-570$

61. Komjati M, Bratusch-Marrain P, Waldhäusl W (1986) Superior efficacy of pulsatile versus continuous hormone exposure on hepatic glucose production in vitro. Endocrinology 118:312-319

62. Stapelfeldt W, Bender H, Shusdziarra V, Pfeiffer EF (1984) Effect of continuous and oscillatory portal vein insulin infusion upon glucose-induced insulin release in rats. Res Exp Med 184: 67-71

63. Maruyama H, Hisatomi A, Orci L, Grodsky GM, Unger RH (1984) Insulin within islets is a physiologic glucagon release inhibitor. J Clin Invest 74: 2296-2299

64. Stagner J, Samols E, Polonsky K, Pugh W (1986) Lack of direct inhibition of insulin secretion by exogenous insulin in the canine pancreas. J Clin Invest 78: 1193-1198

65. Weigle DS, Koerker DJ, Goodner CJ (1984) Pulsatile glucagon delivery enhances glucose production by perifused rat hepatocytes. Am J Physiol 247: E564-E568

66. Weigle DS, Koerker DJ, Goodner CJ (1985) A model for augmentation of hepatocyte response to pulsatile glucagon stimuli. Am J Physiol 248 (Endocrinol Metab 11): E681-E686

67. Weigle DS, Goodner CJ (1986) Evidence that the physiological pulse frequency of glucagon secretion optimizes glucose production by perifused rat hepatocytes. Endocrinology 118: 1606-1613

68. Paolisso G, Scheen AJ, Luyckx AS, Lefèbvre PJ (1987) Pulsatile hyperglucagonemia fails to increase hepatic glucose production in normal man. Am J Physiol 251: E1-E7

69. Rodbell M (1983) The actions of glucagon at its receptor: regulation of adenylate cyclase. In: Lefèbvre PJ (ed) Glucagon I. (Handbook of experimental pharmacology, vol66). Springer, New York, pp 263-290
70. Plas C, Nunez J (1975) Glycogenolytic response to glucagon of cultured fetal hepatocytes. Refractoriness following prior exposure to glucagon. J Biol Chem 250: 5304-5311

71. Blazquez PE, Plant TM, Nakai Y, Keogh EJ, Knobil E (1978) Hypophysial responses to continuous and intermittent delivery of hypothalamic gonadotropin-releasing hormone. Science 202: 631-633

72. Bratusch-Marrain PR, Komjati M, Waldhäusl WK (1986) Efficacy of pulsatile versus continuous insulin administration on hepatic glucose production and glucose utilization in type 1 diabetic humans. Diabetes 35: 922-926

73. Lefèbvre PJ, Luyckx AS (1979) The physiological role of glucagon: a reappraisal. Diabetologia $16: 347-354$

74. Levy-Marchal C, Albisser AM, Zinman B (1983) Overnight metabolic control with pulsed intermittent versus continuous subcutaneous insulin infusion. Diabetes Care 6: 356-360

75. Lilet H, Krzentowski G, Bodson A, Scheen AJ, Lefèbvre PJ (1986) La diminution de moitié de la dose d'insuline administrée par pompe à perfusion sous-cutanée d'insuline (PPSCI) induit une dégradation métabolique nocturne comparable en modes continu et intermittent. Diabete Metab 12: 278 (Abstract)

76. Matthews DR, Burnett MA, Turner RC (1985) Glibenclamide augments basal insulin secretion without restoring normal pulsatility in type II diabetes. Diabetic Med 2: 517A (Abstract)

Professor P.J.Lefèbvre

Hôpital Universitaire de Bavière

Diabétologie

Boulevard de la Constitution, 66

B-4020 Liège

Belgium 